\title{
The Presence of the Body in Digital Education: A Phenomenological Approach to Embodied Experience
}

\author{
Carlos Willatt $^{1}$ (D) Luis Manuel Flores $^{1}$
}

Accepted: 22 November 2021 / Published online: 2 December 2021

(c) The Author(s), under exclusive licence to Springer Nature B.V. 2021

\begin{abstract}
In a context of pervasive digitalization of the social world, both before and during the COVID-19 pandemic, the field of education has undergone major changes with the development of digital practices and settings. However, the physical presence of the subjects and the body remain something primordial and irreplaceable in traditional educational processes. Thus, it is often assumed that virtuality is opposed to the corporeal reality of the subjects involved in teaching, learning and studying. In this paper we aim to critically challenge this assumption by addressing the phenomenon of virtuality in a more original sense: as a fundamental dimension of corporeality itself. Drawing on Merleau-Ponty's phenomenological insights, we argue that the experience of the virtual is inherently embodied and fully real. We understand corporeality and virtuality as entangled and multidimensional phenomena. At the same time, this leads us to rethink the digital as only one possible medium in which virtuality can appear as inherent to embodied experience. We develop our phenomenological approach in three instances. First, we question and bracket two common assumptions about corporeality. From our critical perspective, assumptions about a disembodied digitality and a devirtualized corporeality represent extremes within which educational discourses currently move. Second, we address the inherent virtuality of embodied experience. We outline the heuristic concept of the virtual body (MerleauPonty) to describe corporeality and virtuality as entangled and multidimensional phenomena that encompass extension, intercorporeality and intermediality. Finally, we make some remarks on the relationships of corporeality and virtuality considering the challenges of digital education.
\end{abstract}

Keywords Lived body Embodied experience $\cdot$ Presence $\cdot$ Virtuality $\cdot$ Phenomenology Digital education

Carlos Willatt

cjwillat@uc.cl; carlos.willatt@gmail.com

1 Faculty of Education, Department of Educational Theory and Policy, Pontifical Catholic University of Chile, Vicuña Mackenna 4860, Macul, Santiago de Chile, Chile 


\section{Introduction}

The question of the body and its presence in education has become more urgent than ever due to the COVID-19 pandemic and the resulting suspension of face-to-face activities in schools and universities across the world. Much has been said about the post-pandemic 'new normal' in which digitally-mediated education is no longer the exception, but the norm (OECD 2020; Williamson et al. 2020). Millions of teachers and students are facing great challenges in dealing with both the lack of face-to-face interactions in traditional pedagogical spaces and the compulsive implementation of old and new digital education platforms (Decuypere et al. 2021). Thus, the pandemic has accelerated ongoing processes of digitalization, consolidating a prior understanding of the digital as identical to the virtual or as its most apparent expression (Champion 2019; Grimshaw 2014; Nardi 2015; Ollinaho 2018). Within these processes, little room is left for critical reflections on the relationships between corporeality, virtuality and digitality.

Against this backdrop, the physical presence of the subjects and the body remain something primordial and irreplaceable in pedagogical practice. Thus, it is often assumed that virtuality is opposed to corporeal reality. Indeed, the physical presence is seen as an-if not the - authentic source of the real in contrast to the supposedly disembodied and inauthentic realm of the virtual (Dreyfus 2001, p. 72). Therefore, it is worth asking, once again, to what extent traditional pedagogical practices and settings are being affected or even replaced by virtual modes of teaching, learning and studying. In this paper we will address this question by critically challenging the supposed opposition between corporeality and virtuality.

We argue that such an opposition is misleading since it is based on a technological understanding of the virtual (Steuer 1992). This means that the virtual is thought of from a devicecentered perspective, namely as a specific technological medium: the digital. In the current context of the pervasive digitalization of the social world, electronic devices such as digital computers, tablets or smartphones come to the fore as typical examples of digital media. ${ }^{1}$ Despite the common identification of digital media with the virtual, the term 'digital' - from Latin digitus - originally means something else. It does not refer to technological devices but to the very realm of corporeality, that is, to someone's 10 fingers or toes and, in turn, to the probable origins of the decimal system (Oxford Latin Dictionary 2012, pp. 594-595). In this sense, computation refers to generic processes of symbolic formalization capable of establishing an ordered set of discrete states. These processes are neither disembodied nor exclusive to digital media. Machines and electronic devices (computers) are just as 'computational' as cultural techniques of calculation carried out by humans with pencil and paper. Similarly, the phenomenon of digitalization is not limited to a mere technological process of digitization or transformation of former analogue data (continuous-variable) into digital (non-continuous-discrete) data (Buck 2020).

From a critical and phenomenologically-informed perspective, we propose to move from a technological, device-centered definition towards an experiential description of the virtual. This allows us to approach the phenomenon of virtuality in a more original sense: as

\footnotetext{
${ }^{1}$ Questions concerning the phenomenality, the methodology and the concept of medium are disputed in contemporary media theories and philosophies. This has not least to do with the polysemic nature of the term medium. Indeed, medium can be understood as a "means" or an "instrument", as a "mediator" and a "middle" (Krämer 2015, p. 39). Interestingly, the technological understanding of the virtual implies a tendency to reduce mediality to instrumentality.
} 
a fundamental dimension of corporeality. Thus, our focus is primarily on the experience of the virtual, which enables us to analyze more precisely how virtuality permeates traditional pedagogical practices and settings. Drawing on Merleau-Ponty's phenomenological insights, we argue that the experience of the virtual is inherently embodied and fully real. We understand corporeality and virtuality as entangled and multidimensional phenomena. At the same time, this leads us to rethink the digital as only one possible medium in which virtuality can appear as inherent to embodied experience.

In the educational field, there are many discourses that overlook the inherent virtuality of embodied experience due to the predominance of a technological, device-centered understanding of the virtual and its identification with the digital. Thus, two common and problematic assumptions about corporeality emerge. On the one hand, the assumption of a disembodied digitality in which the body does not play any significant role and it appears as one technological device among others and, on the other hand, the aforementioned assumption that corporeality is a mere physical phenomenon opposed to virtuality. In this case, a point is reached where corporeality is devirtualized. In what follows, we question and bracket both assumptions as they represent extremes within which educational discussions on experiences of the virtual and the digital currently move. From our critical perspective, this step is necessary to develop less biased approaches to the phenomenon of corporeality. ${ }^{2}$ Then, we approach the phenomenon of corporeality by addressing its inherent virtuality. Finally, we make some remarks on the relationship of corporeality and virtuality considering the challenges of digitally-mediated education today.

\section{Disembodied Digitality}

Since pre-pandemic times, the drive for digitalization in the educational field has been closely linked to at least two assumptions. First, the integration of digital technologies into educational processes is a necessary response to the ubiquity of such technologies in the life-world (Lebenswelt) of schools and higher education students. ${ }^{3}$ Since students live in a "cyberculture" (Lévy 2001) and use digital technologies in multiple ways, a rapid transformation of traditional educational institutions (school, university) should be implemented. At the higher education level, the adoption of digital technologies also emerges as a 'solution' for the heterogeneous and changing realities of students, who may be facing complex work and family obligations (Berry and Hughes 2019). In this sense, it seems that the COVID-19 pandemic has only accelerated what was already underway (OECD 2020). Thus, educational institutions should take advantage of technology to avoid becoming obsolete. Second, pre-service and in-service teachers should not only learn how to deal with old and new digital platforms and skills (Van Dijck et al. 2018; Van Dijk and Van Deursen 2014), but they should also adapt quickly to a new type of students: the "digital natives" (Prensky 2001a, 2001b, 2006). According to Prensky's well-known notion (2001a), digital natives 'speak'

\footnotetext{
${ }^{2}$ Following Merleau-Ponty, we assume, at the same time, that completely unprejudiced approaches to experience are impossible (Merleau-Ponty 2005, p. XV).

${ }^{3}$ As part of a multifaceted discourse, these arguments for legitimizing digitalization in education needs to be thought through critically as they places the phenomenon of the digital in a narrative of technological progress that is functional to the so-called "knowledge society" (OECD 2000) and "digital economy" (OECD 2016).
} 
the language of the digital as naturally as their mother tongue. For them, digitalization is an essential part of their way of being in the world (Rosen et al. 2010). Prensky argues that digital technologies can even be regarded as "extensions of their [the students'] brains" (Prensky 2006, p. 11). Despite its simplicity, this notion has successfully entered the international discussion on information and communication technologies (ICT) in education. It is widely spread in the discourse of governments and global institutions that aim to shape policies on digital education (OECD 2017; UNESCO 2011). However, there are good reasons to question these assumptions. We focus here on the notion of digital natives in order to outline some critical aspects.

First, Prensky's notion does not take one of the central tasks of traditional educational institutions seriously, namely, to be a pedagogical space where students learn things they could not otherwise immediately learn by themselves in everyday life. Indeed, school and higher education learning are specific forms of learning that go beyond everyday experiences. They produce a plurality of social and cultural practices, knowledge forms and modes of thinking, as well as abstract languages and symbolic systems. This all means a certain distancing from everyday life. Prensky's notion, instead, neglects the distance between school and everyday life to the extent that everyday experiences of the digital are no longer seen as such in their specificity. Second, this notion reduces the complexity of concrete experiences of the digital as a specific expression of virtuality. Several studies have already shown that its claim to universality is not applicable to all cultural, social, economic, political and educational contexts (Kennedy et al. 2010; Philip and Garcia 2013; Sánchez et al. 2011). Thus, the gap between digital natives and digital "immigrants"- those who grew up in the pre-digital era according to Prensky (2001a, p. 3) — cannot simply be explained in terms of technological or generational differences. ${ }^{4}$ In the context of the COVID-19 pandemic, existing inequalities have been exacerbated and new challenges have arisen. What was once ordinary in much of the world - face-to-face education - may become a privilege of the few. Likewise, what was already a privilege in many places — digital education - may remain a privilege (Dussel et al. 2020).

Last but not least, this notion depicts the body in an instrumental way, that is to say, as a mere tool of the brain. According to Prensky (2001b, 2006), the body of digital natives can be understood as a tool used by the plastic brain to capture stimuli in digital environments. ${ }^{5}$ This cognitive and "neurocentric" perspective (Gallagher 2018, p. 8) reduces human perception to an internal process that occurs in individual and detached brains. Within this computational model of mind and experience (Varela et al. 1991, p. 52-57), cognition takes place as an action "on the basis of representations that are physically realized in the form of a symbolic code in the brain" (Varela et al. 1991, p. 40). The body does not play a significant role and, in turn, could supposedly even be replaced entirely by other devices (Kurzweil 2005). In short, these assumptions remain closely tied to a technological, device-centered perspective that defines the body as one device among others. As we will see, such a per-

\footnotetext{
${ }^{4}$ Technological and generational differences are usually discussed under the notion of digital divide. However, the common definition of the digital divide is insufficient to explain the complexity of technological experiences as it focuses more on quantitative issues of access to ICT (Compaine 2001). In fact, the availability of digital technologies does not guarantee their 'competent' use. For this reason, some authors (Cabello and Claro 2017) advocate a less simplistic understanding of this divide, which also includes qualitative differences in the use of ICT (individual skills, social, economic, cultural, political factors, etc.).

5 'Plastic' in terms of neuroplasticity.
} 
spective fails to do justice to both the specific experience of the virtual and the digital and the phenomenon of corporeality.

\section{Devirtualized Corporeality}

Since their emergence and massification in the $20^{\text {th }}$ century, digital technologies have caused suspicion and rejection. The main argument for rejecting them in educational contexts is based on the naturalization of face-to-face pedagogical classroom experiences. Indeed, face-to-face teaching in classrooms is characterized as the natural pedagogical situation par excellence, which operates as a reference point and norm of authenticity. As the common expression 'brick-and-mortar classroom' suggests, a pedagogical space is understood here as identical to the physical space of the classroom. Thus, any pedagogical form or setting that deviates from that is regarded as less authentic, incomplete or deficient. At best, digitally-mediated education would be one of the possible "approximations" to authentic face-to-face classroom situations (Grossman et al. 2009, p 2079). This would be the case of pedagogical experiences in virtual classrooms where the physical absence of both the body and the classroom appears as the most evident deficit. Although digitally-mediated education encompasses both asynchronous and synchronous modes, the attempt to 'approximate' face-to-face classroom situation is most clearly seen in the case of virtual classroom via synchronous videoconferencing and its variants. ${ }^{6}$ Depending on the possibilities of the software or platform, synchronous virtual classrooms allow a dynamic and real-time interaction with others much like face-to-face interaction (Martin and Parker 2014). However, as long as the face-to-face classroom situation remains the standard of pedagogical authenticity a typical situation of digitally-mediated education such as those in fully synchronous virtual classrooms via videoconferencing seems to be deficient in several ways:

a) Body fragmentation and disproportion: online meetings are usually face-centered situations that make the rest of the body disappear. Furthermore, our body and the bodies of others on screen are shown in proportions that differ from face-to-face situations (sometimes bigger, sometimes smaller) and they emphasize different visual perspectives, alter color, people's age, etc.

b) Lack of eye contact: since the camera and the display screen are in different spots, it is technically impossible to simultaneously 'look into the eye' (camera) when looking at the eyes of someone on screen.

c) Body at the limits of perception: unlike face-to-face situations, when engaged in a videoconference we can be present without being seen or heard at all (for instance, if our camera and microphone are turned off).

d) Audiovisual interruptions: meetings can be interrupted at any time and for reasons beyond human control: the sound cuts out, the image 'freezes', we hear background noise or audio feedback, etc.

\footnotetext{
${ }^{6}$ In the context of distance education, asynchronous modes of teaching, learning and studying have a long history dating back to epistolary exchanges and correspondence education (Moore and Diehl 2019). With the emergence and massification of analogue and digital electronic devices and the internet, online asynchronous and synchronous modes begin to coexist and to be used in a 'pure' and/or mixed way. Thus, for example, the synchronous mode has variants such as the so-called 'synchronous hybrid or blended learning environment' in which both on-site and remote students can simultaneously attend pedagogical activities (Raes et al. 2019).
} 
e) Decentered pedagogical space: the fully synchronous virtualclassroom establishes a specific spatiality in which hierarchies and roles of traditional pedagogical settings become diffuse. Teachers and students share a common virtual space that has no fixed center.

f) Body aches and pains: after hours of sitting in front of a computer screen, new aches and pains may appear: eye fatigue, stiff neck, tendinitis, cramps, etc.

Moreover, the naturalization of the face-to-face classroom experience often takes on a defensive tone. What is defended is both the supposed naturalness of this experience and a deep-rooted Western idea of children and childhood as innocent and pure (Baader 2018). In fact, the rejection of the digital becomes dogmatic due to a protectionist and moralistic attitude towards digital technologies, focused almost exclusively on potential risks and threats to children and adolescents (cyberbullying, grooming, sexting, phubbing, etc.). ${ }^{7}$

Nevertheless, the assumptions about the naturalness of face-to-face classroom experiences are just as problematic as the assumptions related to 'digital nativeness'. These assumptions not only operate as prejudices that neglect the inherent virtuality of embodied experience, but also lead to simplistic judgments about technological phenomena in general and about digital technologies in particular. ${ }^{8}$ The naturalization of the physical presence reduces the body to a mere object of the physical world alongside other physical bodies and devices. Furthermore, the identification of the pedagogical space with the physical space of the classroom - 'brick-and-mortar classroom' - does not do justice to the experiential dimension involved in the relations of space and place (Relph 1976; Tuan 2001). The classroom as a 'pedagogical space' is not limited to a physical setting where 'objects'-walls, windows, blackboards, desks, chairs, books, etc.- and 'subjects' - teachers and studentsare located. The classroom is also a "humanized space" (Tuan 2001, p. 54) where embodied and intersubjective experiences and practices such as teaching, learning and studying take place. As a physical space, the classroom evokes atmospheres and moods through its shapes, materials, colors, smells, etc. Pedagogical practices intervene that space fostering particular situations, dynamics and environments. Thus, the pedagogical space is experienced as a place where both personal and shared meanings arise that go beyond the mere fact of being located in a physical space. Certainly, the ways in which we inhabit the physical space of the face-to-face classroom differ from the ways in which we inhabit the virtual classroom. However, this difference does not mean that the experience of the virtual classroom is the experience of something inauthentic or less real. Rather, the virtual classroom can be regarded as a virtual place that demands specific ways of involvement, engagement and attachment (Champion 2019; Relph 2007). Certain experiences and practices in the virtual classroom can develop a specific sense of place that is not so much based on sharing a physical space, but on sharing a feeling of 'being there' and 'being together' involved in both individual and collective activities (Lehman and Conceiçao 2010; Osler 2020).

From a technological, device-centered perspective, digitally-mediated pedagogical situations such as those via synchronous videoconferencing are certainly a relatively new expression of virtuality in human history. From an experiential perspective, however, the

\footnotetext{
${ }^{7}$ This moralistic attitude should be put into perspective with approaches that analyze both the risks and opportunities offered by digital technologies (Cabello-Hutt et al. 2018; Livingstone and Helsper 2010).

${ }^{8}$ Before judging for or against technological phenomena, it is necessary to describe their complexities and ambivalences. In this sense, technology "is neither good nor bad; nor is it neutral." (Kranzberg 1986, p. 545).
} 
digital is rather one possible medium in which virtuality can appear as inherent to embodied experience. Therefore, it is necessary to examine the ways in which the virtual unfolds in the embodied experience itself in order to understand digitality as a specific expression of virtuality.

\section{Virtualizing Embodied Experience}

After bracketing common assumptions about corporeality in the context of digital education, we can approach the phenomenon of corporeality by addressing its inherent virtuality. For this purpose, we focus on Merleau-Ponty's early work, particularly on the Phenomenology of perception first published in 1945. In recent years, there has been a growing interest in Merleau-Ponty's approach to the phenomenon of virtuality due to its potential to rethink corporeality in the experience of the virtual (Alloa 2014; Barbaras 1999; du Toit 2020; Ihde 2009; Parmentier 2018; Steeves 2001; Vitali-Rosati 2010, 2016). We draw on Merleau-Ponty's critical reformulation of intentionality as an expression of virtual corporeal movement in order to outline the concept of the virtual body (corps virtuel). We understand the virtual body as a heuristic concept that enables a critical analysis of the entanglement of corporeality and virtuality. ${ }^{9}$ It also allows us to describe extension, intercorporeality and intermediality as fundamental dimensions of corporeal virtuality and presence.

\section{Intentionality and Corporeal Virtuality}

Husserl has previously recognized that the body is an intricate phenomenon. In fact, it cannot be described as a simple "thing" (Ding) of our experience in the world because experience is somehow co-constituted by the body (Husserl 2000, p. 167). The consciousness of having a body (Körper) — given in a certain way, exposed, vulnerable, measurable, intervened and located in an 'objective' space and time alongside other physical bodies — presupposes a more original experience: the experience of being that body. As Husserl points out, the lived body that we are (Leib) is the "zero point" (Nullpunkt) of all our experiences and orientations (Husserl 2000, p. 166; italics in original), the "transfer-point" (Umschlagstelle) between the natural and the spiritual (Husserl 2000, p. 299). Spatial relations of distance and position, as well as perspective, movement and affection, are possible due to the lived body that we are in and towards the world.

The difficulties that arise when attempting to describe the body involve a fundamental tension between language and experience (Husserl 1982, p. 38). We usually talk about the body that we have (Körper), our physical body, as if we were in possession of a mundane thing or an object of the 'external world'. We refer to our body in an objectifying manner, which is, however, inevitable to some extent. Nevertheless, the experience of the lived body that we are (Leib) cannot be reduced to a verbal description of an external thing or object that 'becomes alive' only within a process of introspection or conscious self-perception. ${ }^{10}$

\footnotetext{
${ }^{9}$ This concept has nothing to do with the transhumanist concept of virtual body (Kurzweil 2005) that tends towards a disembodied digitality, that is to say, it aims at overcoming human corporeality by means of digitalization.

${ }^{10}$ Husserl's classic example cited by Merleau-Ponty (2005, p. 106) is the tactile self-perception. By touching the other hand, each hand is at the same time able to perceive itself (Husserl 2000 p. 152).
} 
Our embodied experience is rather expressive on its own and does not need to be first thought out or represented in order to gain reality. This is a crucial insight that MerleauPonty develops in his critical approach to Husserl's Phenomenology.

In the Phenomenology of perception, Merleau-Ponty reformulates the phenomenological notion of intentionality, which means to be directed towards something. He understands the sensorimotor dimension of the body - the entanglement of perception and movement - as an "original intentionality" (Merleau-Ponty 2005, p. 158). ${ }^{11}$ Unlike the "intentionality of act" (Aktintentionalität) attributed to consciousness as a consciousness of something (Bewussteinvon-etwas) (Merleau-Ponty 2005, p. 486), this intentionality is an engaged, pre-reflective and non-objectifying intentionality that emerges from our corporeal "anchorage" in the world (Merleau-Ponty 2005, p. 167). In other words, it is not primarily the consciousness, but the body that is directed to the world. Since we are already bodily engaged with the world, we can have a consciousness of it. Therefore, the embodied experience does not take place in terms of the Cartesian cogito, that is, as an "I think", but as an "I can" (Merleau-Ponty 2005, p. 159). For example, when we walk to our desk we do not think about every single joint and muscle movement involved in the act of walking itself, but we can simply move our limbs to do so. We just move towards our desk. The body does not express itself based on internal representations of the world as an object formed in a transcendental consciousness or in a detached brain. Instead, it is itself expression in and towards the world with which it is engaged.

Interestingly, what we perceive bodily and sensually arouses a "host of intentions", a surplus that calls upon the body as a "center of virtual action" towards the body itself and the world (Merleau-Ponty 2005, p. 125). Thus, the intentional act of perception opens up a horizon of corporeal virtuality that is not exhausted in actual movements of the body. As Merleau-Ponty puts it:

each stimulus applied to the body [...] arouses a kind of 'virtual movement', rather than an actual one; the part of the body in question sheds its anonymity, is revealed, by the presence of a particular tension, as a certain power of action within the framework of the anatomical apparatus. (Merleau-Ponty 2005, p. 125)

In the emergence of this corporeal virtuality from intentionality, the senses "intercommunicate by opening on to the structure of the thing" (Merleau-Ponty 2005, p. 266). Thus, the embodied experience takes place as an "intersensory experience" (Merleau-Ponty 2005, p. 255). For example, the sense of sight is stimulated when we see a cup of coffee on our desk. If we pick up the cup and drink the coffee, other senses such as touch, smell and taste are also stimulated. However, tactile, olfactory or gustatory experiences are not exhausted in what we are actually touching, smelling or tasting, in some way like regular coffee drinkers can already 'touch', 'smell' or even 'taste' the cup of coffee with their gaze and feel the tension it produces in their body, especially when they are sleepy and thirsty. In this case, just looking at the cup arouses virtual movements towards it that may or may not be actualized in concrete actions.

Although these virtual movements are not necessarily visible to others, they can be experienced and described from a first-person perspective. In this respect, the practice of pantomime has a paradigmatic character. The mime moves in a world that is invisible to us, but which we can nevertheless perceive. For example, the mime can inhabit a house. Although we do not see the house, we know that he inhabits it because of the movements he actual-

${ }^{11}$ Merleau-Ponty draws on the Husserlian notion of "operative intentionality" (fungierende Intentionalität). 
izes: he can open a door, enter and lie down on his bed. That house, physically absent, is virtually present. What amuses us and generates admiration in this situation is that the mime makes precise and subtle movements to inhabit a house that is physically invisible and absent, but still real.

\section{The Entanglement of Embodied and Virtual Presence}

The phenomenon of corporeality challenges one-dimensional and static descriptions of presence. Indeed, the body is not merely present as a fixed physical reference point that works on the basis of pre-defined distances or positions in an objective space but, rather, it establishes contingent relations in the concrete situation in which it is engaged by unfolding a corporeal virtuality. Thus, the body can be present both physically and virtually.

In order to address the virtual presence of the body, in the Phenomenology of perception Merleau-Ponty draws on an experiment by German Gestalt psychologist Max Wertheimer, who investigated the optical perception of movement. In this experiment, a subject is asked to observe the room where he is solely through an inclined mirror. The mirror reflects the room at an angle of 45 degrees to the vertical. Thus, things seen through the mirror appear oblique: walls, doors, a man walking around in the room, a falling cardboard tube. However, after a few minutes, a sudden change occurs: the person begins to see all reflected things straight (Wertheimer 1912, p. 258). According to Merleau-Ponty, this experiment is significant for two reasons. On the one hand, it shows that the visual field can impose an orientation which differs from that of the body. On the other hand, the body "as an agent" can spontaneously establish new levels of orientation without any motor exploration in the physical space (Merleau-Ponty 2005, p. 290). Thus, the subject who observes the room through the mirror projects himself on the reflected thing and "the reflected room miraculously calls up a subject capable of living in it [...] he inhabits the spectacle." (Merleau-Ponty 2005, p. 291).

Following Merleau-Ponty, we can describe the body that unfolds corporeal virtuality as a virtual body, that is, the body as projected into a medium other than the medium of the physical body. The virtual body reorganizes its spatial-temporal relationships in order to inhabit the medium in which it appears. But what is the status of this projection? What is its relationship with the physical body? In this respect, Merleau-Ponty claims that what counts in the embodied experience is not the body:

as it in fact is, as a thing in objective space, but as a system of possible actions, a virtual body with its phenomenal 'place' defined by its task and situation. My body is wherever there is something to be done. (Merleau-Ponty 2005, p. 291)

In other words, the virtual body transgresses the domain of the physical body that we have (Körper) as a given thing in a measurable space and time, but without overcoming it. In a certain way, the physical body remains a reference point described in terms of an object of the 'external world'. On the contrary, the phenomenal place of the virtual body is not given beforehand. The virtual body is located neither 'before' nor 'after' the physical body. It instead emerges in the very engagement with tasks and situations. ${ }^{12}$

\footnotetext{
${ }^{12}$ Alloa (2014, p. 154) suggests that the emergence of the virtual body presupposes a sort of "virtual space" (espace virtuel). An in-depth analysis of this notion, which Merleau-Ponty introduces in his seminal work The Structure of Behavior (1963), is beyond the scope of this paper. For a further discussion on this subject, see Parmentier (2018).
} 
Even though the emerging virtual body adjusts to the spatial-temporal possibilities offered by the medium in which it is projected, the subject of experience never completely abandons the realm of the physical. The virtual body does not imply an escape from reality, but a deeper engagement with it (Steeves 2001). This does not prevent the subject from having the feeling of being immersed in another world. Such a feeling can be explained in terms of "transposition" (Merleau-Ponty 2005, p. 292). The phenomenon of transposition has its origin in the field of music. In everyday life, we can observe transposition events when someone without any musical knowledge sings a tune heard previously, but in another key. We can observe this phenomenon, for example, when non-musicians sing the very wellknown Happy Birthday song.

Considering the experience of transposition, Merleau-Ponty claims that the virtual body "ousts the real one to such an extent that the subject no longer has the feeling of being in the world where he actually is" (Merleau-Ponty 2005, p. 291). Although the adjective 'real' may be confusing in this passage, Merleau-Ponty does not use it to mean that the virtual body involved in the transposition is inauthentic or less real than the physical one. Instead, the virtual body is real in terms of being perceived and experienced as a projection in a specific medium, even if this projection has not yet been actualized by concrete actions of the physical body. In other words, the virtual body coexists with the physical body as a relatively autonomous projection and a transgression of the latter in another medium. The coexistence of the physical and the virtual body also shows that the phenomenon of simultaneity seems to be constitutive of the virtual. Indeed, the body remains attached to the realm of the physical while simultaneously projecting itself onto another medium. Therefore, the presence of the virtual body is fully real and by no means neutral: it affects the subject from which it emerges as projection. Hence, the 'ousting' of the real body mentioned by MerleauPonty should be understood in terms of virtual movement and reorganization of the human sensorium.

In the Phenomenology of perception, Merleau-Ponty implicitly relates the presence of the virtual body as a projection to an idea of technology as an extension of the human body. Although he never developed a theory of technology, several analyses and reflections on technological phenomena can be found in his work (Hoel and Carusi 2017; Ihde 2009). Thus, he argues that, for example, a blind man who habitually uses a stick to walk no longer perceives the stick as an external device. Rather, the stick becomes an instrument of his own perception, an extension of his touch (Merleau-Ponty 2005, p. 165). Interestingly, this very idea is explicitly developed by other thinkers. In the late 19th century, German philosopher Ernst Kapp outlined a theory of technology as a projection of human organs (Kapp 1877). Kapp understands technology as a broad cultural phenomenon comprising media, artifacts and tools produced by humans in their historical development. Thus, for example, a hammer emerges as projection of the human hand. In the $20^{\text {th }}$ century, Canadian media theorist Marshall McLuhan developed his own thesis of projection in terms of extension. Like Kapp and Merleau-Ponty, McLuhan understands technology as an extension of the human body, although he also warns that any extension induces at the same time a state of numbness or "self-amputation" of the physical body that "demands new ratios or new equilibriums among the other organs and extensions of the body" (McLuhan 1994, p. 45). In other words, technology emerges from a dynamic and intricate process of corporeal extensions and self-amputations that continuously reorganizes the human sensorium. 
For example, the wheel as an extension of the human body made the creation of new means of transport possible, which reduced both the physical effort and the time needed for travel. At the same time, it also increased burdens by bringing about "a new intensity of action by its amplification of a separated or isolated function (the feet in rotation)" (McLuhan 1994, p. 42). Thus, the wheel somehow 'numbs' the feet and induces an immediate relief of strain that radically modifies the spatial-temporal experience of traveling. With this, new forms of organization of human life emerged. However, the wheel does not serve humans merely as a means to an end (traveling). It profoundly transforms human experience by accelerating the rhythm of life and, in turn, humans may end up being servants of the rule of speed that it imposes.

What is more, the virtual body as a present and extended body is never isolated. It appears and coexists with human and non-human, non-virtual and virtual bodies. Interestingly, Merleau-Ponty suggests that intersubjectivity and virtuality are interrelated phenomena. He claims that the intersubjective dimension of embodied experience begins "as soon as we designate a point in space with our finger" (Merleau-Ponty 1964, p. 7; italics in original). Thus, this pointing gesture refers to both the actual place from which it is done and to an (virtual) elsewhere as its correlate (Alloa 2014, p. 154). As the virtual body is situated in the real world between bodies and in relation to them, "intercorporeality" (intercorporéité) stands out as an elemental dimension of presence (Merleau-Ponty 1977, p. 173). Indeed, the first relationship of the virtual body is with the physical body from which it emerges - and which it displaces - as a sort of representation-extensiontransgression in a specific medium. The 'hybrid' status of the virtual body as a representation-extension-transgression can be clearly experienced in computer-based digital environments. ${ }^{13}$ For example, digital images of the human body displayed on computer screens cannot be properly understood according to any of the 'typical' modes of representation (Vorstellung) identified by Heidegger (1985, pp. 40-44). We experience a digital picture of ourselves not simply as a bodily presence (Leibhaftigkeit) which is physically given and stands for itself: we are $i n$ the picture displayed on screen but we are not the picture; nor as empty intending (Leermeinen), that is, as something we talk about, imagine or even hallucinate and which is not bodily present: we can actually see the picture on-screen in front of us; nor as a mere 'picture-thing' (Bildding) which stands for something else: the displayed picture shows us, but is itself not a simple physical thing like a postcard that shows the Inca citadel Machu Picchu.

Moreover, intercorporeality implies the phenomenon of intermediality. The medium in which the virtual body appears is not an isolated medium. It is instead conceivable only in relation to other media (McLuhan 1994, p. 26). Thus, intermediality in digital environments should be understood in at least two senses. On the one hand, digital media exist in relation to non-digital media such as hardware and physical bodies. On the other hand, intermediality means a constant and intricate interplay of diverse media and senses such as images (vision), sounds (audition) and surfaces (touch).

\footnotetext{
${ }^{13}$ Most computer-based digital environments today consist of hardware and software drawing on the architecture of the electronic digital computer outlined by Hungarian-American mathematician and physicist John von Neumann (Von Neumann, 1945). In simple terms, this architecture consists of a central processing unit (CPU) that includes an arithmetic logic unit (ALU), processor registers and a control unit (instruction register and program counter), a main memory for storing data and instructions, external mass storage, and input and output mechanisms that allow human interaction.
} 


\section{Final Remarks}

In this paper we have attempted to approach the relationship between corporeality and virtuality by tackling virtuality as a fundamental dimension of corporeality. Drawing on Merleau-Ponty's phenomenological insights, we have described virtuality as inherent to embodied experience. This, however, does not mean that virtuality is corporeal in an exclusively human sense. In this respect, Merleau-Ponty's understanding of the virtual in the Phenomenology of perception remains rather ambivalent and moves between experiential descriptions of human corporeal virtuality and instrumental approaches to technology and media as non-human phenomena. Therefore, it is necessary to rethink the status of the perceiving body in the emergence of the virtual. Indeed, in the Phenomenology of perception Merleau-Ponty does not question the primacy of the body as a subject, whereby the fundamental assumption about the "possession of the world by my body" remains problematic (Merleau-Ponty 2005, p. 291). As long as technology is thought of primarily from an anthropocentric perspective in terms of a "projective teleology" (Alloa 2014, p. 155), it is not possible to do justice to the otherness and strangeness of non-human virtual technologies (Parisi 2013). ${ }^{14}$ Nevertheless, some authors (Alloa 2014; du Toit 2020; Hoel and Carusi 2017; Vitali-Rosati 2010, 2016) suggest that Merleau-Ponty's later writings allow us to reconsider the emergence of the virtual in a non-anthropocentric way by introducing the concept of flesh (chair) (Merleau-Ponty 1968). In any case, the heuristic concept of the virtual body has allowed us to examine some of the ways in which the body itself transgresses its physical presence without overcoming it, by opening up a horizon of virtual corporeal movement and meaning. Therefore, digital environments in which the body can appear-for example when videoconferencing-should be regarded instead as specific expressions of corporeal virtuality.

By considering virtuality as constitutive of embodied experience, the question of the body and its presence in education shifts to the question of specific media and modes in which virtuality appears. Such a shift compels us to rethink the mediality of pedagogical processes and practices. Indeed, we should go beyond any instrumental understanding of media in terms of mere means for the realization of certain instructional or educational purposes. Pedagogical means-forms, operations, practices, arrangements, settings - and media - understood here not only as instruments, but also as mediators and irreducible third parties (Krämer 2015) - should rather be thought of in relation to one another.

What is more, it is necessary to examine the spatial-temporal differences that emerge from the media in which corporeal virtuality unfolds. From an analytical point of view, a fundamental difference is to be found between embodied and virtual presence. Whereas the body as an actual physical presence can be here or there, the virtual body can be here and there. This difference allows us to relate the modes of embodied and virtual presence to phenomena of sequentiality and simultaneity. In fact, simultaneity seems to be constitutive of the virtual regardless of the specific medium in which it may appear. This aspect is of utmost importance when analyzing the relationship between pedagogical means and media. We note that the specific digital virtuality tends towards simultaneity by unfolding in media such as images. Although media are never isolated, the predominance of images goes hand in hand with a privileging of vision in Western cultures (ocularcentrism). By putting vision - alongside audition and, to a lesser extent, touch — at the center of experiences

${ }^{14}$ This criticism may also applies to Kapp's and McLuhan's theories. 
in digital environments such as synchronous videoconferencing, we are confronted not only with a simplification of experience, but also of virtuality itself. Similar to the experience of traditional face-to-face classroom (Marini 2021), the experience of synchronous virtual classroom via videoconferencing often focuses on what lies ahead and is 'visible'. That is to say, the screen of the electronic device becomes the front that dominates the attention. However, digital technologies - like all technologies - are ambivalent. Since the body-through the visual field - can spontaneously establish new levels of orientation without any motor exploration in the physical space (Merleau-Ponty 2005), the 'virtual front' is not limited to the physical, visual front. The body as a virtual body allows us to explore and inhabit spaces in very different and novel ways. In this regard, it makes sense to think about new approaches to space and place in the context of, for example, place-based education (Smith and Sobel 2010). Certainly, the excessive use of digital media can be alienating and lead to a disconnection from the immediate environment and the needs of the local community where teachers and students live. Nevertheless, digital media can also help cultivate a sense of place in the geographic territory. Indeed, it is possible to get involved in problem-solving within a local community by using digital media to explore physical spaces. Digitally-mediated spatial exploration - through, for example, online collaborative mapping (Sandy and Franco 2014) or immersive, interactive virtual field trips (Mead et al. 2019) — can foster a virtual sense of geographic place (Relph 2007), which may precede, accompany or vary an in-person exploration of the physical space without replacing it.

At the same time, it is important to think of ways to pedagogically address the complexity of the human sensorium by making other intersensory, individual and social experiences of non-digital virtuality possible, for example, by means of olfactory and gustatory experiences both inside and outside the classroom. ${ }^{15}$ Interestingly, the processes of massive confinement and digitalization forced by the COVID-19 pandemic have revitalized experiences of non-digital virtuality that may be pedagogically significant. For example, in the experience of baking bread at home, virtuality can appear in different ways: in relation to corporeal movements while kneading the dough, when varying the ingredients, in the memories and emotions evoked by a family recipe, etc. This experience allows us to observe and address a wide range of physical, biological and chemical processes of varying complexity. Indeed, if the bread dough is made from wheat flour, we can analyze the relationship between the movements involved in kneading and the formation of a strong and elastic network of gluten that gives the dough a particular consistency. By observing fermentation and baking processes, we can address biological functions, physical changes and chemical reactions as interesting and complex as the Maillard reaction, which explains the characteristic color, aroma, flavor and texture of freshly baked bread. Of course, this experience also takes us back to one of the oldest human cultural practices. We can ask, for example, about the historical, economic, political and cultural transformations experienced by the production and

\footnotetext{
${ }^{15}$ Literature provides wonderful examples of experiences of non-digital virtuality. The famous madeleine scene in Marcel Proust's monumental novel In Search of Lost Time can be interpreted as a classic example of a temporal (present-past) experience of non-digital, olfactory and gustatory virtuality. After tasting a piece of a 'petite madeleine' cake steeped in lime-blossom tea, the narrator notes: "The sight of the little madeleine had recalled nothing to my mind before I tasted it; perhaps because I had so often seen such things in the meantime, without tasting them, on the trays in pastry-cooks' windows, that their image had dissociated itself from those Combray days to take its place among others more recent; [...] But when from a long-distant past nothing subsists, after the people are dead, after the things are broken and scattered, taste and smell alone, more fragile but more enduring, more immaterial, more persistent, more faithful, remain poised a long time, like souls, remembering, waiting, hoping, amid the ruins of all the rest” (Proust 1992, pp. 63-64).
} 
consumption of bread over time. Last but not least, we can experience personal and shared aesthetic moments with others. After all, a crusty bread fresh from the oven can and should be seen, smelled, touched, heard and eaten.

Moreover, the fact that the limits of the body become diffused in the entanglement of corporeality and virtuality does not mean that the body has no limits. There is a surplus of meaning in the embodied experience itself that cannot be simply 're-presented' in other media. Such a surplus exposes the limits of the body. Indeed, the body expresses a sort of engaged and pre-reflective "interiority" (Henry 1975, p. 38) that does not depend on processes of introspection, conscious self-perception or representation.

In short, as one of the possible modes of the virtual, it is necessary to consider digitality in its specificity beyond the compulsion of the 'new digital normal'. At the same time, we should not allow the digital to be the only expression of virtuality that we can experience. Virtuality and digitality must be distinguished accordingly. Otherwise, we reinforce common assumptions about corporeality in experiences of the virtual and the digital and neglect the opportunity to radically question technical developments and supposed 'solutions' for teaching, learning and studying offered in the field of digital education. Perhaps one of the great challenges of today's education is precisely to make other non-digital virtualities possible that are capable of doing justice to the plurality of embodied experience.

Acknowledgements We would like to thank Guillermo Marini and Guido Couck for their kind readings and advice on earlier versions of this paper. We would also like to thank our two anonymous reviewers for their helpful comments.

Funding This work was supported by the Chilean National Agency for Research and Development through the Grant ANID FONDECYT Postdoctoral 3200018.

Availability of Data and Material Not applicable.

Code Availability Not applicable.

\section{Declarations}

Conflicts of Interest/Competing Interests The authors have no conflicts of interest to declare that are relevant to the content of this article.

\section{References}

Alloa, Emmanuel. 2014. The theatre of the virtual: how to stage potentialities with Merleau-Ponty. In Encounters in performance philosophy, eds. Laura Cull and Alice Lagaay, 147-170. London: Palgrave Macmillan.

Baader, Meike Sophia. 2018. Longing for innocence and purity: nature and child-centered education. In Encyclopedia of educational philosophy and theory, ed. Michael A. Peters, 1304-1310. Singapore: Springer.

Barbaras, Renaud. 1999. Merleau-Ponty aux limites de la phénoménologie. Chiasmi International 1: 199-212.

Berry, Gregory, and Heidi Hughes. 2019. Integrating work-life balance with 24/7 information and communication technologies: the experience of adult students with online learning. American Journal of Distance Education 34 (2): 1-15.

Buck, Marc Fabian. 2020. Of chimæras and trojan horses - Critical remarks on digitalization in democratic societies. In Demokratieerziehung und die Bildung digitaler Öffentlichkeit, eds. Ulrich Binder and Johannes Drerup, 83-196. Wiesbaden: Springer. 
Cabello-Hutt, Tania, Patricio Cabello, and Magdalena Claro. 2018. Online opportunities and risks for children and adolescents: The role of digital skills, age, gender and parental mediation in Brazil. New Media $\&$ Society 20 (7): 2411-2431.

Cabello, Patricio, and Magdalena Claro. 2017. Public policies for digital inclusion among young people in Chile: reflections on access, opportunities, outcomes and rights. Journal of Children and Media 11 (2): 248-251.

Champion, Erik. 2019. The phenomenology of real and virtual places. New York: Taylor \& Francis.

Compaine, Benjamin. 2001. The digital divide. Facing a crisis or creating a myth? Cambridge, Massachusetts: MIT Press.

Decuypere, Mathias, Emiliano Grimaldi, and Paolo Landri. 2021. Introduction: Critical studies of digital education platforms. Critical Studies in Education 62 (1): 1-16.

Dreyfus, Hubert. 2001. On the internet. London: Routledge.

Dussel, Inés, Patricia Ferrante, and Darío, and Pulfer. 2020. Pensar la educación en tiempos de pandemia: entre la emergencia, el compromiso y la espera. Buenos Aires: UNIPE Editorial Universitaria.

$\mathrm{Du}$ Toit, Jean. 2020. Living in the age of the embodied screen. Indo-Pacific Journal of Phenomenology 20 (1): $1-9$.

Gallagher, Shaun. 2018. Decentering the brain: Embodied cognition and the critique of neurocentrism and narrow-minded philosophy of mind. Constructivist Foundations 14 (1): 8-21.

Grimshaw, Mark. 2014. The Oxford Handbook of Virtuality. Oxford: Oxford University Press.

Grossman, Pam, Christa Compton, Danielle Igra, Matthew Ronfeldt, Emily Shahan, and Peter Williamson. 2009. Teaching practice: a cross-professional perspective. Teachers College Record 111 (9): 2055-2100.

Heidegger, Martin. 1985. History of the concept of time. Prolegomena. Bloomington: Indiana University Press.

Henry, Michel. 1975. Philosophy and phenomenology of the body. The Hague: Martinus Nijhoff.

Hoel, Aud Sissel, and Annamaria Carusi. 2017. Merleau-Ponty and the measuring body. Theory, Culture and Society 35 (1): 45-70.

Husserl, Edmund. 1982. Cartesian meditations. An introduction to phenomenology. Dordrecht: Martinus Nijhoff.

Husserl, Edmund. 2000. Ideas pertaining to a pure phenomenology and to a phenomenological philosophy. Second book: Studies in the phenomenology of constitution. Dordrecht: Kluwer Academic Publishers.

Ihde, Don. 2009. Postphenomenology and technoscience. The Peking University lectures. New York: SUNY Press.

Kapp, Ernst. 1877. Grundlinien einer Philosophie der Technik. Zur Entstehungsgeschichte der Kultur aus neuen Gesichtspunkten. Braunschweig: George Westermann.

Kennedy, Gregor, Terry Judd, Barney Dalgarno, and Jenny Waycott. 2010. Beyond natives and immigrants: exploring types of net generation students. Journal of Computer Assisted Learning 26 (5): 332-343.

Krämer, Sybille. 2015. Medium, messenger, transmission. An approach to media philosophy. Amsterdam: Amsterdam University Press.

Kranzberg, Melvin. 1986. Technology and History: “Kranzberg's Laws”. Technology and Culture 27 (3): 544-560.

Kurzweil, Ray. 2005. The Singularity is near: When humans transcend biology. New York: Viking.

Lehman, Rosemary M., and O. C. Simone, and Conceiçao. 2010. Creating a sense of presence in online teaching. How to "be there" for distance learners. San Francisco, CA: Jossey-Bass.

Lévy, Pierre. 2001. Cyberculture. Minneapolis: University of Minnesota Press.

Livingstone, Sonia, and Ellen Helsper. 2010. Balancing opportunities and risks in teenagers' use of the internet: the role of online skills and internet self-efficacy. New Media \& Society 12: 309-329.

Marini, Guillermo. 2021. An introduction to everyday aesthetics in education. Studies in Philosophy and Education 40 (1): 39-50.

Martin, Florence, and Michele A. Parker. 2014. Use of synchronous virtual classrooms: why, who, and how? Journal of Online Learning and Teaching 10 (2): 192-210.

McLuhan, Marshall. 1994. Understanding media. The extensions of man. Cambridge, Massachusetts: MIT Press.

Mead, Chris, Sanlyn Buxner, Geoffrey Bruce, Wendy Taylor, Steven Semken, and Ariel D. Anbar. 2019. Immersive, interactive virtual field trips promotescience learning. Journal of Geoscience Education 67 (2): $131-142$.

Merleau-Ponty, Maurice. 1963. The structure of behavior. Boston: Beacon Press.

Merleau-Ponty, Maurice. 1964. An unpublished text by Maurice Merleau-Ponty: a prospectus of his work. In The primacy of perception and other essays on phenomenological psychology, the philosophy of art, history and politics, ed. James M. Edie, 3-11. Evanston: Northwestern University Press.

Merleau-Ponty, Maurice. 1968. The visible and the invisible. Followed by working notes. Evanston: Northwestern University Press. 
Merleau-Ponty, Maurice. 1977. Signs. Illinois: Northwestern University Press.

Merleau-Ponty, Maurice. 2005. Phenomenology of perception. London and New York: Routledge.

Moore, Michael, and William C. Diehl. 2019. Handbook of distance education. New York: Routledge.

Nardi, Bonnie. Virtuality. 2015. Annual Review of Anthropology 44: 15-31.

OECD. 2000. Knowledge Management in the Learning Society. https://read.oecd-ilibrary.org/education/ knowledge-management-in-the-learning-society_9789264181045-en\#page1. Accessed 4 May 2021.

OECD. 2016. New skills for the digital economy. Measuring the demand and supply of ICT skills at work. https:/www.oecd-ilibrary.org/docserver/5jlwnkm2fc9xen.pdf? expires=1594937091\&id=id\&accname $=$ guest $\&$ checksum $=8$ E0275980F40F5876F401555D625362D. Accessed 4 May 2021.

OECD. 2017. OECD Science, Technology and Industry Scoreboard 2017. The digital transformation. https:// www.oecd-ilibrary.org/docserver/9789264268821-en.pdf?expires=1594941372\&id=id\&accname=gue st\&checksum=B7C96F5A0F1C005C41B6CFCEB827371C. Accessed 4 May 2021.

OECD. 2020. Education Responses to Covid-19: Embracing Digital Learning and Online Collaboration. https://read.oecd-ilibrary.org/view/?ref=120_120544-8ksud7oaj2\&title=Education_responses_to_ Covid-19_Embracing_digital_learning_and_online_collaboration. Accessed 4 May $202 \overline{1}$.

Ollinaho, Ossi. 2018. Virtualization of the life-world. Human Studies 41: 193-209.

Osler, Lucy. 2020. Feeling togetherness online: a phenomenological sketch of online communal experiences. Phenomenology and the Cognitive Sciences 19 (3): 569-588.

Oxford Latin Dictionary. 2012. Oxford: Oxford University Press.

Parmentier, Marc. 2018. Espace, mouvement et corps virtuels chez Merleau-Ponty. Methodos 18. https://doi. org/10.4000/methodos.5014.

Parisi, Luciana. 2013. Contagious architecture. Computation, aesthetics, and space. Cambridge MA: MIT Press.

Philip, Thomas, and Antero Garcia. 2013. The importance of still teaching the iGeneration. New Technologies and the Centrality of Pedagogy. Harvard Educational Review 83 (2): 300-319.

Prensky, Marc. 2001a. Digital natives, digital immigrants, part 1. On the Horizon 9 (5): 1-6.

Prensky, Marc. 2001b. Digital natives, digital immigrants, part 2. On the Horizon 9 (6): 1-9.

Prensky, Marc. 2006. Listen to the natives. Educational Leadership 63 (4): 8-13.

Proust, Marcel. 1992. In search of lost time. Volume 1. Swann's Way. New York: The Modern Library.

Raes, Annelies, Loulou Detienne, Ine Windey, and Fien Depaepe. 2019. A systematic literature review on synchronous hybrid learning: gaps identified. Learning Environments Research 23: 269-290.

Relph, Edward. 1976. Place and placelessness. London: Pion.

Relph, Edward. 2007. Spirit of place and sense of place in virtual realities. Techné: Research in Philosophy and Technology 10 (3): 17-25.

Rosen, Larry, L. Mark Carrier, and Nancy A. Cheever. 2010. Rewired: Understanding the iGeneration and the way they learn. New York: Palgrave Macmillan.

Sánchez, Jaime, Alvaro Salinas, and David Contreras, and Eduardo Meyer. 2011. Does the new digital generation of learners exist? A Qualitative Study. British Journal of Educational Technology 42 (4): 543-556.

Sandy, Marie G., and Zeno E. Franco. 2014. Grounding service-learning in thedigital age: exploring a virtual sense of geographic place through onlinecollaborative mapping and mixed media. Journal of Higher Education Outreach and Engagement 18 (4): 201-232.

Smith, Gregory, and David Sobel. 2010. Place- and community-based education in schools. New York: Routledge.

Steeves, James. 2001. The virtual body: Merleau-Ponty?s early philosophy of imagination. Philosophy Today 45 (4): $370 ? 380$.

Steuer, Jonathan. 1992. Defining virtual reality: dimensions determinig telepresence. Journal of Communication 42 (4): 73-93.

Tuan, Yi-Fu. 2001. Space and place: the perspective of experience. Minneapolis: University of Minnesota Press.

UNESCO. 2011. Digital natives: How do they learn? How to teach them? https://iite.unesco.org/pics/publications/en/files/3214698.pdf. Accessed 4 May 2021.

Van Dijck, José, Thomas, Poell, and Martijn De Waal. 2018. The platform society: Public values in a connective world. Oxford: Oxford University Press.

Van Dijk, Jan, and Alexander Van Deursen. 2014. Digital skills. Unlocking the information society. New York: Palgrave Macmillan.

Varela, Francisco, Evan Thompson, and Eleanor Rosch. 1991. The embodied mind: Cognitive science and human experience. Cambridge: MIT Press.

Von Neumann, John. 1945. First Draft of a Report on the EDVAC. https://web.archive.org/ web/20130314123032/http://qss.stanford.edu/ godfrey/vonNeumann/vnedvac.pdf. Accessed 4 May 2021.

Vitali-Rosati, Marcello. 2010. Corps et virtuel. Itinéraires à partir de Merleau-Ponty. Paris: L'Harmattan. 
Vitali-Rosati, Marcello. 2016. The chiasm as a virtual. A non-concept in Merleau-Ponty's work (with a coda on theatre). In Merleau-Ponty and the art of perception, eds. Duane H. Davis, and William S. Hamrick, 279-296. New York: SUNY Press.

Wertheimer, Max. 1912. Experimentelle Studien über das Sehen von Bewegung. Zeitschrift für Psychologie 61 (1): 161-265.

Williamson, Ben, and Rebecca Eynon, and John Potter. 2020. Pandemic politics, pedagogies and practices: Digital technologies and distance education during the coronavirus emergency. Learning, Media and Technology 45 (2): 107-114.

Publisher's Note Springer Nature remains neutral with regard to jurisdictional claims in published maps and institutional affiliations. 